\title{
Analisis Kelengkapan Pengisian Berkas Rekam Medis Pasien Rawat Inap RSUP Dr. Kariadi Semarang
}

\author{
Selvia Juwita Swari ${ }^{1}$, Gamasiano Alfiansyah ${ }^{2}$, Rossalina Adi Wijayanti ${ }^{3}$, Rowinda Dwi Kurniawati ${ }^{4}$ \\ ${ }^{1,2,3,4)}$ Program Studi Rekam Medik, Jurusan Kesehatan, Politeknik Negeri Jember \\ E-mail : ${ }^{1}$ selvia@polije.ac.id, ${ }^{2}$ gamasiano.alfiansyah@polije.ac.id, \\ ${ }^{3}$ rossa@polije.ac.id, ${ }^{4}$ rowinda09@gmail.com
}

\begin{abstract}
ABSTRAK
Data kelengkapan berkas rekam medis pada bulan Desember 2018, Januari 2019 dan Februari 2019 belum 100\% lengkap. Hal tersebut belum memenuhi Standar Minimal Pelayanan Rumah Sakit. Ketidaklengkapan pengisian berkas rekam medis akan mengakibatkan catatan yang termuat menjadi tidak sinkron serta informasi kesehatan pasien terdahulu sulit diidentifikasi. Tujuan penelitian untuk mengidentifikasi kelengkapan pengisian berkas rekam medis dan faktor penyebab ketidaklengkapan pengisian berkas rekam medis pasien rawat inap RSUP Dr. Kariadi Semarang tahun 2019. Penelitian ini merupakan penelitian kualitatif. Subjek penelitian terdiri dari 2 orang petugas PJRM. Objek penelitian adalah sampel berkas rekam medis rawat inap tanggal 25-28 Februari 2019 berdasar rumus slovin sebanyak 86 berkas. Hasil penelitian terhadap kelengkapan identitas pasien, kelengkapan laporan penting, kelengkapan autentifikasi berkas rekam medis rawat inap dan kelengkapan pencatatan yang benar menunjukkan bahwa kelengkapan pengisian rekam medis dilihat dari ke empat aspek tersebut cukup tinggi. Ketidaklengkapan pengisian berkas rekam medik rawat inap disebabkan oleh beberapa faktor yaitu faktor petugas (man), faktor prosedural (method), faktor alat (material), faktor machines dan faktor motivation.
\end{abstract}

Kata kunci: Kelengkapan, rekam medis, rawat inap

\section{ABSTRACT}

The completeness of medical record file in December 2018, January 2019 and February 2019 is not complete, so it does not Fulfill the Minimum Standards of Hospital Services. The incomplete filling of medical record files will cause the records to be out of sync and the patient's previous health information difficult to identify. The purpose of the study was to identify the completeness of filling medical record files and the factors causing incompleteness of filling medical record files for inpatients at RSUP Dr. Kariadi Semarang. This research was a qualitative research. The research subjects consisted of 2 officers in charge of medical records. The object of the study was 86 samples of inpatient medical record files from 25-28 February 2019 based on the Slovin formula. The results of the research that the completeness of the patient's identity, the completeness of important reports, the completeness of inpatient medical record file authentication and the completeness of correct recording, indicated that the completeness of filling the medical record was quite high. The incompleteness of filling in the inpatient medical record file was caused by several factors, specifically the officer factor (man), procedural factor (method), tool factor (material), machine factor and motivation factor.

Keywords: completeness, medical records, inpatient

*Korespondensi Author : Selvia Juwita Swari, Politeknik Negeri Jember, selvia@polije.ac.id, 081332033399

\section{PENDAHULUAN}

Rumah sakit sebagai salah satu fasilitas pelayanan kesehatan rujukan tingkat lanjutan bertujuan untuk menyelenggarakan pelayanan kesehatan baik secara promotif, preventif, kuratif, maupun rehabilitatif. Rumah sakit bertanggung jawab untuk meningkatkan mutu pelayanan kesehatan kepada pasien. Mutu pelayanan kesehatan dapat dicapai dengan penilaian beberapa aspek, salah satunya adalah kualitas kelengkapan pengisian berkas rekam medis. ${ }^{1}$

Kelengkapan pengisian berkas rekam medis harus mencapai angka 100\% selama 1x24 jam setelah pasien keluar rumah sakit. ${ }^{2}$ Rekam medis sebagai catatan perjalanan penyakit pasien merupakan berkas yang pengisiannya harus terisi secara lengkap. Ketidaklengkapan pengisian berkas rekam medis akan mengakibatkan catatan yang termuat menjadi tidak sinkron serta 
informasi kesehatan pasien terdahulu sulit diidentifikasi. $^{3}$

RSUP Dr. Kariadi Semarang merupakan rumah sakit rujukan wilayah Jawa Tengah. Pengisian berkas Rekam Medis (RM) rawat inap di RSUP Dr. Kariadi dilakukan oleh dokter dan perawat dan harus kembali ke ruang PJRM (Penanggung Jawab RM/Assembling) 1x24 jam setelah pasien keluar RS. Apabila berkas RM belum lengkap, maka berkas akan dikembalikan ke bangsal masing-masing untuk dilengkapi dalam kurun waktu 1x24 jam berikutnya. Data kelengkapan berkas sebagaimana tabel 1 .

\section{Tabel 1. Data Kelengkapan Berkas RM}

\begin{tabular}{cccccc}
\hline \multirow{2}{*}{$\begin{array}{l}\text { N } \\
\mathrm{o}\end{array}$} & \multirow{2}{*}{ Bulan } & $\begin{array}{l}\text { Jumlah } \\
\text { Berkas }\end{array}$ & $\begin{array}{c}\text { An24 } \\
\text { jam }\end{array}$ & $\begin{array}{c}2 \times 24 \\
\text { jam }\end{array}$ & $\begin{array}{c}\geq 3 \\
\text { hari }\end{array}$ \\
\hline \multirow{2}{*}{1} & $\begin{array}{l}\text { Desember } \\
2018\end{array}$ & \multirow{2}{*}{4247} & $\begin{array}{c}2720 \\
(64 \%)\end{array}$ & $\begin{array}{c}361 \\
(8 \%)\end{array}$ & $\begin{array}{c}152 \\
(3 \%)\end{array}$ \\
\hline \multirow{2}{*}{$\begin{array}{l}2 \\
2\end{array}$} & $\begin{array}{l}\text { Januari } \\
2019\end{array}$ & \multirow{2}{*}{4280} & $\begin{array}{c}2959 \\
(69 \%)\end{array}$ & $\begin{array}{c}608 \\
(14 \%)\end{array}$ & $\begin{array}{c}713 \\
(17 \%)\end{array}$ \\
\hline \multirow{2}{3}{3} & $\begin{array}{l}\text { Februari } \\
2019\end{array}$ & \multirow{2}{*}{3380} & $\begin{array}{c}2780 \\
(82 \%)\end{array}$ & $\begin{array}{c}534 \\
(16 \%)\end{array}$ & $\begin{array}{c}66 \\
(2 \%)\end{array}$ \\
\hline
\end{tabular}

Berdasarkan tabel 1, berkas RM rawat inap pada bulan Desember 2018 sampai dengan Februari 2019 mencapai 4247 berkas dengan angka kelengkapan pengisian berkas rekam medis belum mencapai angka $100 \%$. Dampak dari permasalahan pengisian berkas RM rawat inap yang tidak lengkap akan mengganggu mutu pelayanan kesehatan di RSUP Dr. Kariadi Semarang. ${ }^{4}$ Tidak lengkapnya informasi kesehatan dalam berkas RM rawat inap akan mengakibatkan sulitnya identifikasi kondisi atau riwayat penyakit pasien terdahulu dan berisiko untuk terjadinya salah pengobatan. ${ }^{5}$

\section{METODOLOGI}

Jenis penelitian yang akan digunakan adalah penelitian kualitatif. Kualitatif adalah penelitian yang dilakukan karena peneliti ingin mengeksplore fenomena-fenomena yang tidak dapat dikuantitatifkan yang bersifat deskriptif seperti proses suatu langkah kerja, formula suatu resep, pengertian-pengertian tentang suatu konsep yang beragam, karakteristik suatu barang dan jasa, gambar-gambar, gaya-gaya, tata cara suatu budaya, dan model fisik suatu artifak. ${ }^{6}$ Subjek penelitian terdiri dari 2 orang petugas
PJRM (Penanggung Jawab RM). Objek penelitian adalah sampel berkas rekam medis rawat inap tanggal 25-28 Februari 2019 berdasar rumus slovin.

Tabel 2. Jumlah Berkas Rawat Inap

\begin{tabular}{ccc}
\hline No & Tanggal & Jumlah \\
\hline 1 & 25 Februari 2019 & 109 berkas \\
\hline 2 & 26 Februari 2019 & 159 berkas \\
\hline 3 & 27 Februari 2019 & 174 berkas \\
\hline 4 & 28 Februari 2019 & 156 berkas \\
\hline & Total & 598 berkas
\end{tabular}

Sampel berkas rekam medis:

$$
\begin{aligned}
\mathrm{n} & =\frac{\mathrm{N}}{1+\mathrm{Ne} 2} \\
& =\frac{598}{1+598(0,01)} \\
& =85,6 \\
& =86 \text { berkas }
\end{aligned}
$$

sehingga diperoleh sampel berkas rekam medis rawat inap sebesar 86 berkas.

\section{HASIL DAN PEMBAHASAN}

\section{A. Analisis Kelengkapan Identifikasi Pasien}

Kelengkapan pengisian identitas pada lembar rekam medis sangat penting untuk menentukan milik siapa lembaran tersebut. Lembar identitas pasien dapat menjadi alat untuk identifikasi pasien secara spesifik. Setiap lembaran data sosial pasien pada berkas rekam medis minimal memuat data berupa nomor rekam medis, nomor registrasi, nama pasien, jenis kelamin, tempat dan tanggal lahir, agama, alamat lengkap, status perkawinan, dan pekerjaan

\begin{tabular}{|c|c|c|c|c|}
\hline \multirow{3}{*}{$\begin{array}{c}\text { Komponen } \\
\text { Analisis }\end{array}$} & \multicolumn{3}{|c|}{ Jumlah } & \multirow{3}{*}{ Tota } \\
\hline & \multicolumn{2}{|c|}{ Ada } & Tidak & \\
\hline & Benar & Salah & Ada & \\
\hline 1. No RM & 86 & 0 & 0 & 86 \\
\hline $\begin{array}{ll}2 . & \text { No } \\
& \text { Register }\end{array}$ & 86 & 0 & 0 & 86 \\
\hline $\begin{array}{ll}\text { 3. } & \text { Nama } \\
& \text { Lengkap } \\
\end{array}$ & 86 & 0 & 0 & 86 \\
\hline $\begin{array}{ll}\text { 4. } & \text { Jenis } \\
& \text { Kelamin } \\
\end{array}$ & 86 & 0 & 0 & 86 \\
\hline $\begin{array}{l}\text { 5. Tempat, } \\
\text { Tanggal } \\
\text { Lahir }\end{array}$ & 86 & 0 & 0 & 86 \\
\hline 6. Agama & 86 & 0 & 0 & 86 \\
\hline 7. Alamat & 86 & 0 & 0 & 86 \\
\hline
\end{tabular}
pasien. $^{7}$ Data kelengkapan identifikasi pasien sebagaimana tabel 3 .

Tabel 3. Data Kelengkapan Identitas Pasien 


\begin{tabular}{llcccc}
\hline 8. & $\begin{array}{l}\text { Status } \\
\text { Perkawi- } \\
\text { nan }\end{array}$ & 86 & 0 & 0 & 86 \\
\hline 9. & Pekerjaan & 86 & 0 & 0 & 86 \\
\hline
\end{tabular}

Tabel 3 menunjukkan bahwa jumlah pengisian terhadap sembilan komponen data identitas secara benar ada 86 berkas rekam medis. Jumlah berkas yang sembilan komponennya tidak terisi sebanyak 0 berkas rekam medis. Kesimpulannya berkas rekam medis yang menjadi sampel seluruhnya memuat data sosial pasien yang terisi secara lengkap dan benar (sesuai dengan kartu identitas milik pasien). ${ }^{7}$

\section{B. Analisis Kelengkapan Laporan Penting}

Kelengkapan pengisian yang laporan penting pada berkas rekam medis rawat inap meliputi data yang sifatnya sangat penting dalam memantau perkembangan penyakit pasien. Data laporan yang penting dalam berkas rekam medis antara lain diagnosis utama, keadaan keluar, tanggal masuk Rumah Sakit, jenis operasi, laporan operasi, dan informed consent. Laporan tersebut akan memberikan informasi tentang tindakan yang dilakukan oleh dokter dan perawat dalam merawat pasien, sehingga diharapkan memuat informasi yang akurat, lengkap, dan dapat dipercaya. ${ }^{8}$ Data kelengkapan laporan yang penting dalam berkas rekam medis rawat pasien rawat inap sebagaimana tabel 4 .

Tabel 4. Data Kelengkapan Laporan Penting

\begin{tabular}{|c|c|c|c|c|}
\hline \multirow{3}{*}{$\begin{array}{c}\text { Komponen } \\
\text { Analisis }\end{array}$} & \multicolumn{3}{|c|}{ Jumlah } & \multirow{3}{*}{ Total } \\
\hline & \multicolumn{2}{|c|}{ Ada } & \multirow{2}{*}{$\begin{array}{l}\text { Tidak } \\
\text { Ada }\end{array}$} & \\
\hline & Benar & Salah & & \\
\hline Diagnosis Utama & 86 & 0 & 0 & 86 \\
\hline $\begin{array}{c}\text { Keadaan Keluar } \\
\text { Pasien }\end{array}$ & 86 & 0 & 0 & 86 \\
\hline $\begin{array}{c}\text { Tanggal Masuk } \\
\text { RS } \\
\end{array}$ & 86 & 0 & 0 & 86 \\
\hline $\begin{array}{c}\text { Hasil } \\
\text { Laboratorium / } \\
\text { Radiologi }\end{array}$ & 86 & 0 & 0 & 86 \\
\hline Jenis Operasi & 72 & 14 & 0 & 86 \\
\hline $\begin{array}{c}\text { Laporan } \\
\text { Tindakan Operasi }\end{array}$ & 72 & 14 & 0 & 86 \\
\hline Informed Consent & 72 & 14 & 0 & 86 \\
\hline $\begin{array}{l}\text { Tabel } \\
\text { diagnosa utama, } \mathrm{k} \\
\text { RS, dan hasil lak } \\
\text { lengkap dan bena } \\
\text { rekam medis }\end{array}$ & $\begin{array}{l}\text { men } \\
\text { eadaan } \\
\text { atau } \\
\text { untuk }\end{array}$ & $\begin{array}{l}\text { njukkan } \\
\text { celuar, } t \\
\text { adiologi }\end{array}$ & $\begin{array}{r}\text { kon } \\
\text { anggal } \\
\text { terisi }\end{array}$ & $\begin{array}{l}\text { onen } \\
\text { lasuk } \\
\text { ecara } \\
\text { erkas } \\
\text { rkas. }\end{array}$ \\
\hline
\end{tabular}

Komponen jenis operasi, laporan tindakan atau operasi, dan informed consent terisi secara lengkap pada 72 berkas rekam medis, sedangkan sisanya sejumlah 14 berkas rekam medis tidak terisi secara lengkap.

\section{Analisis Kelengkapan Autentifikasi Berkas Rekam Medis Rawat Inap}

Autentifikasi yaitu suatu proses yang merupakan sebuah tindakan pembuktian (validasi) terhadap identitas seseorang, dalam hal ini yaitu dokter atau perawat yang memiliki kewenangan untuk mengisi berkas rekam medis pasien. Autentifikasi dapat berupa nama terang, tanda tangan, cap/stempel dan inisial yang dapat diidentifikasi dalam rekam medis atau kode seseorang untuk komputerisasi. Autentifikasi dalam hal pengisiannya di berkas rekam medis berkaitan dengan dokter penanggung jawab pasien dan perawat yang menangani pasien selama perawatan rawat inap ${ }^{8}$ Data kelengkapan autentifikasi berkas rekam medis rawat inap sebagaimana tabel 5 .

Tabel 5. Data Kelengkapan Autentifikasi Berkas Rekam Medis Rawat Inap

\begin{tabular}{|c|c|c|c|c|}
\hline \multirow{3}{*}{$\begin{array}{c}\text { Komponen } \\
\text { Analisis }\end{array}$} & \multicolumn{3}{|c|}{ Jumlah } & \multirow{3}{*}{ Total } \\
\hline & \multicolumn{2}{|c|}{ Ada } & \multirow{2}{*}{$\begin{array}{c}\text { Tidak } \\
\text { Ada }\end{array}$} & \\
\hline & Benar & Salah & & \\
\hline $\begin{array}{l}\text { 1. Checklist } \\
\text { Kepulangan }\end{array}$ & 63 & 23 & 0 & 86 \\
\hline $\begin{array}{l}\text { 2. Resume } \\
\text { Pasien Keluar }\end{array}$ & 82 & 4 & 0 & 86 \\
\hline $\begin{array}{l}\text { 3. Assesment } \\
\text { awal } \\
\end{array}$ & 69 & 17 & 0 & 86 \\
\hline $\begin{array}{l}\text { 4. Diagnosa } \\
\text { Keperawatan }\end{array}$ & 86 & 0 & 0 & 86 \\
\hline $\begin{array}{l}\text { 5. Lembar } \\
\text { Terintegrasi }\end{array}$ & 72 & 0 & 14 & 86 \\
\hline $\begin{array}{l}\text { 6. Asuhan } \\
\text { Keperawatan }\end{array}$ & 67 & 19 & 0 & 86 \\
\hline $\begin{array}{l}\text { 7. Rencana } \\
\text { Pemulangan }\end{array}$ & 86 & 0 & 0 & 86 \\
\hline $\begin{array}{l}\text { 8. Lembar } \\
\text { edukasi }\end{array}$ & 86 & 0 & 0 & 86 \\
\hline $\begin{array}{l}\text { 9. Hasil } \\
\text { Radiologi } \\
\text { dan/ } \\
\text { Laboratorium } \\
\end{array}$ & 75 & 5 & 6 & 86 \\
\hline $\begin{array}{l}\text { 10. Persetujuan } \\
\text { /Penolakan } \\
\text { Tindakan } \\
\end{array}$ & 86 & 0 & 0 & 86 \\
\hline
\end{tabular}




\begin{tabular}{lcccc}
\hline $\begin{array}{c}\text { 11. Laporan } \\
\text { Operasi }\end{array}$ & 83 & 0 & 3 & 86 \\
\hline $\begin{array}{c}\text { 12. Informed } \\
\text { Consent }\end{array}$ & 86 & 0 & 0 & 86 \\
\hline
\end{tabular}

Berdasarkan tabel 5, komponen diagnosa keperawatan, rencana pemulangan, lembar edukasi, persetujuan/penolakan tindakan dan informed consent memuat autentifikasi pada seluruh berkas yang dijadikan sampel yaitu 86 berkas rekam medis. Komponen checklist kepulangan memiliki kelengkapan autentifikasi secara benar sejumlah 63 berkas rekam medis. Penelitian autentifikasi secara benar pada komponen resume pasien keluar sebanyak 82 berkas, pada komponen assesment awal sebanyak 69 berkas, pada komponen lembar terintegrasi sebanyak 72 berkas rekam medis, pada komponen asuhan keperawatan sebanyak 67 berkas, dan pada komponen hasil radiologi dan/ laboratorium sebanyak 75 berkas, serta pada laporan operasi sebanyak 83 berkas rekam medis.

\section{Analisis Kelengkapan Pencatatan yang Benar}

Pencatatan dalam berkas rekam medis harus selalu dilakukan dengan cara yang benar karena berkas rekam medis merupakan catatan penting yang harus diperhatikan penelitiannya. Apabila terjadi kesalahan pencatatan dalam berkas rekam medis tidak dibenarkan untuk melakukan penghapusan dengan cara apapun. Untuk mengkoreksinya adalah dengan cara bagian yang salah digaris (dicoret) namun, catatan tersebut harus masih bisa terbaca. Kemudian diberi catatan disampingnya bahwa catatan tersebut salah. Terakhir ditambahkan paraf dari petugas yang bersangkutan. Data kelengkapan pencatatan yang benar sebagaimana tabel 6.

Tabel 6. Data Kelengkapan Pencatatan yang

\begin{tabular}{ccccc}
\multicolumn{5}{c}{ Benar } \\
\hline \multirow{2}{*}{$\begin{array}{c}\text { Komponen } \\
\text { Analisis }\end{array}$} & \multicolumn{4}{c}{ Jumlah } \\
\cline { 2 - 5 } Ada & Benar & Salah & Tidak Ada & Total \\
\hline $\begin{array}{c}\text { Penelitian } \\
\text { Diagnosa }\end{array}$ & 86 & 0 & 0 & 86 \\
\hline Keterbacaan & 72 & 14 & 0 & 86 \\
\hline $\begin{array}{c}\text { Pembetulan } \\
\text { Kesalahan }\end{array}$ & 11 & 0 & 75 & 86 \\
\hline
\end{tabular}

Berdasarkan Tabel 6, komponen penulisan diagnosa sebanyak 86 berkas rekam PUSLITBANG Sinergis Asa Professional, Jember medis. Komponen keterbacaan tulisan dokter memiliki jumlah sebanyak 72 berkas rekam medis. Artinya sisa sampel berkas yang ada yaitu sebanyak 14 berkas membutuhkan konfirmasi ulang terhadap dokter yang bersangkutan. Komponen pembetulan penelitian yang benar ditemukan pada 11 berkas rekam medis, dan sisanya sebanyak 75 berkas rekam medis tidak memuat pembetulan tulisan.

Berdasarkan hasil penelitian (tabel 3, 4, 5 dan 6), diperoleh data bahwa kelengkapan pengisian rekam medis dilihat dari ke-empat aspek dapat dikatakan cukup tinggi. Hal ini berarti pada penelitian ini angka ketidaklengkapan pengisian berkas rekam medis lebih rendah dibandingkan dengan angka kelengkapan pengisiannya. Hal ini menunjukkan bahwa mutu pelayanan yang diselenggarakan di RSUP Dr. Kariadi Semarang dapat dikatakan baik.

Pernyataan ini didukung oleh teori yang mengatakan bahwa hasil analisis kelengkapan berkas rekam medis menentukan peringkat suatu unit atau sarana kesehatan. ${ }^{5}$ Apabila hasil analisis dari sebagian besar berkas rekam medis baik dapat disimpulkan mutu pelayanan kesehatan yang diselenggarakan adalah baik, berarti unit atau sarana pelayanan kesehatan tersebut termasuk unit atau sarana pelayanan kesehatan yang mutu pelayanan kesehatannya adalah baik. ${ }^{9}$

Rekam medis yang berkualitas adalah rekam medis yang berisi data secara lengkap, sehingga dapat diolah menjadi sebuah informasi. ${ }^{10}$ Arti dari pernyataan diatas adalah sebuah rekam medis yang bermutu selalu akan terisi lengkap oleh data dan mampu diolah menjadi informasi yang bermanfaat sebagai pembuktian dalam perkara hukum sehingga tidak menyulitkan dokter dalam menghadapi tuntutan malpraktek.

Kelengkapan pengisian berkas rekam medis sangat penting dilakukan karena salah satu kegunaan dari berkas rekam medis, jika dilihat dari aspek hukum merupakan bahan tanda bukti tertulis. Hasil analisis yang telah dilakukan terhadap kelengkapan pengisian berkas rekam medis di RSUP Dr. Kariadi Semarang dapat dikatakan telah memenuhi syarat sebagai bahan 
bukti tertulis. Jika berkas rekam medis tersebut digunakan sebagai bukti tertulis, kekuatan hukumnya cukup kuat.

\section{E. Faktor Penyebab Ketidaklengkapan Pengisian Berkas Medis Rawat Inap}

Ketidaklengkapan pengisian berkas rekam medik rawat inap disebabkan oleh beberapa faktor yaitu faktor petugas (man), faktor prosedural (method), faktor alat (material), faktor machines dan faktor motivation. Faktor man penyebab ketidaklengkapan pengisian berkas rekam medik yaitu kurangnya tingkat kesadaran dan kedisiplinan dokter dalam melengkapi berkas rawat inap sehingga dokter tidak segera menandatangani berkas rekam medik rawat inap. Tanda tangan dan nama dokter pada rekam medis sifatnya sangat penting karena merupakan legalitas dan bentuk tanggung jawab terhadap pasien. Setiap pencatatan ke dalam rekam medis harus dibubuhi nama, waktu dan tanda tangan dokter, dokter gigi atau tenaga kesehatan tertentu yang memberikan pelayanan kesehatan secara langsung. ${ }^{3}$

Faktor method berkas rekam medik rawat inap adalah kegiatan monitoring ketidaklengkapan terhadap ketidaklengkapan masih belum efektif karena petugas rekam medis yang melakukan monitoring harus berkeliling memasuki seluruh ruangan rawat inap. Selain itu petugas monitoring memiliki tugas lain yaitu melakukan coding untuk klaim di rawat jalan sehingga kegiatan monitoring belum bisa berjalan dengan efektif. Penyebab lainnya adalah belum ada evaluasi SPO pengisian berkas rekam medik rawat inap. Berdasarkan hasil observasi dapat diketahui bahwa isi dari SPO pengisian berkas rekam medik rawat inap yang ada di unit rekam medik rawat inap masih belum spesifik. SPO tersebut tidak mencantumkan batas waktu untuk melengkapi berkas rekam medik rawat inap. Standar prosedur operasional atau SOP memberikan langkah yang benar dan terbaik dalam rekam medis berdasarkan konsensus bersama untuk melaksanakan berbagai kegiatan dan fungsi pelayanan yang dibuat oleh sarana pelayanan kesehatan berdasarkan standar profesi. Direktur rumah sakit wajib membuat prosedur kerja tetap penyelenggaraan rekam medis di rumah sakit masing-masing. ${ }^{3}$ Sejalan dengan teori tersebut petugas diharuskan untuk menjadikan SOP sebagai pedoman dalam bekerja untuk menyelesaikan proses kerja rutin dalam hal ini pengisian dokumen rekam medis rawat inap agar dapat berjalan dengan baik.

Faktor material penyebab ketidaklengkapan pengisan berkas rekam medik rawat inap 24 jam setelah selesai pelayanan adalah tidak adanya data rekapitulasi ketidaklengkapan pengisan berkas rekam medik rawat inap di setiap ruang rawat inap. Berdasarkan hasil wawancara dengan petugas ruangan tidak terdapat data rekapitulasi ketidaklengkapan pengisian pengisan berkas rekam medik rawat inap. Data ketidaklengkapan dapat dibuat dengan menulis di buku atau langsung dmasukkan dalam microsoft excel. Pada data ketidaklengkapan dapat memuat nama dokter dan item apa saja yang belum terisi dengan lengkap sehingga nantinya dapat diketahui dokter siapa saja yang sering tidak melengkapi pengisan berkas rekam medik rawat inap. Adanya data tersebut dapat memudahkan kepala ruangan untuk melakukan evaluasi terkait ketidaklengkapan pengisian pengisan berkas rekam medik rawat inap.

Faktor machine penyebab ketidaklengkapan pengisian berkas rekam medik rawat inap 24 jam setelah selesai pelayanan adalah lembar cheklist penilaian kelengkapan pengisian berkas rekam medik rawat inap belum spesifik. Berdasarkan hasil observasi dapat dilihat bahwa lembar cheklist yang digunakan oleh tim monitoring untuk memeriksa kelengkapan pengisian berkas rekam medik di setiap ruangan rawat inap masih belum spesifik. Pada lembar tersebut hanya berisi penilaian kelengkapan dari formulir laporan operasi, laporan anestesi dan resume medis saja. Apabila ada lembar lain yang tidak terisi dengan lengkap maka petugas akan menuliskan satu persatu lembar mana saja yang tidak terisi lengkap.

Faktor motivation penyebab ketidaklengkapan pengisan berkas rekam medik rawat inap 24 jam setelah selesai pelayanan adalah tidak ada sanksi yang tegas terkait ketidaklengkapan pengisian berkas rekam medik 
rawat inap. Pemberian sanksi bertujuan untuk menghindari terjadinya atau pengulangan suatu pelanggaran atau kesalahan yang dilakukan oleh seorang pegawai misalnya dalam hal keterlambatan pengembalian berkas rekam medis. Sanksi dimunculkan bagi seorang karyawan yang melakukan kesalahan dan pelanggaran agar termotivasi untuk menghentikan perilaku menyimpang dan mengarahkan pada perilaku positif, sehingga dengan diberikannya sanksi yang tegas diharapkan dapat meminimalisir terjadinya ketidaklengkapan pengisian dokumen berkas rekam medis rawat inap. ${ }^{11}$ Penyebab lainnya dari faktor motivation yaitu tidak adanya pendorong semangat bekerja seperti adanya penghargaan atau hadiah atau hanya sebatas pujian kepada petugas. Penghargaan dimunculkan untuk memotivasi seseorang supaya giat dalam menjalankan tanggung jawab karena terdapat anggapan bahwa dengan pemberian hadiah atas hasil pekerjaannya, karyawan akan lebih bekerja maksimal. ${ }^{11}$

\section{SIMPULAN DAN SARAN}

Berdasarkan uraian hasil dan pembahasan dari penelitian tentang analisis ketidaklengkapan pengisian dokumen rekam medis rawat inap 24 jam setelah pelayanan di RSUP Dr. Kariadi Semarang dapat diambil kesimpulan sebagai berikut: Unsur man, dokter tidak segera menandatangani berkas rekam medis rawat inap disebabkan kurangnya tingkat kedisiplinan dan kesadaran dokter untuk mengisi berkas rekam medis. Unsur method, kegiatan monitoring terhadap ketidaklengkapan pengisian berkas rekam medis kurang efektif dan belum ada evaluasi SPO pengisian berkas rekam medis rawat inap. Unsur material, tidak ada data ketidaklengkapan berkas rekam medis rawat inap di setiap ruang rawat inap. Unsur machine, lembar checklist penilaain kelengkapan pengisian berkas rekam medis rawat inap belum spesifik. Unsur motivation, tidak ada sanksi yang tegas terkait ketidaklengkapan pengisian berkas rekam medis rawat inap dan tidak adanya pendorong semangat bekerja seperti adanya penghargaan atau hadiah atau hanya sebatas pujian kepada petugas.

Saran yang mungkin dapat digunakan untuk meningkatkan kelengkapan pengisian berkas rekam medis rawat inap di RSUP Dr. Kariadi Semarang yaitu, Unsur man, perlu adanya teguran dari kepala ruangan kepada dokter yang sering tidak mengisi DRM secara lengkap, kemudian mengadakan rapat secara rutin setiap 1 bulan sekali dengan menghadirkan ketua bidang rekam medis, kepala ruangan rawat inap, dan para dokter. Kepala rekam medik dapat menyampaikan terkait data ketidaklengkapan pengisian rekam medis rawat inap. Dokter dapat memberikan tanggapan berupa sanggahan maupun penjelasan mengenai penyebab seringnya tidak mengisi berkas rekam medik secara lengkap sehingga nantinya kepala ruangan rawat inap dapat membatu memberikan masukan agar tidak ada lagi dokter yang mengisi berkas rekam medik secara tidak lengkap. Unsur method, mengadakan sosialisasi SOP tentang pengisian dokumen rekam medis rawat inap, mengadakan evaluasinya secara rutin (satu bulan sekali) dengan mengikutsertakan semua petugas terkait dengan ketidaklengkapan pengisian DRM rawat inap, melakukan evaluasi SPO pengisian berkas rekam medik rawat inap, membuat buku pencatatan atau ekspedisi terkait ketidaklengkapan pengisian DRM rawat inap disetiap ruang rawat inap. Pada buku tersebut berisi nama dokter, item yang belum lengkap, tanggal pelayanan, dan tanda tangan dokter jika sudah dilengkapi. Unsur machine, memperbaiki lembar checklist penilaian kelengkapan pengisian berkas rekam medik rawat inap. Unsur motivation, memberikan sanksi yang tegas terhadap dokter yang sering tidak melengkapi berkas rekam medik rawat inap. Sanksi tersebut dapat berupa teguran secara langsung atau pemberian surat peringatan bagi dokter yang tidak mengisi berkas rekam medik rawat inap secara lengkap. Memberikan penghargaaan berupa penambahan gaji remunerasi kepada dokter yang mengisi DRM rawat inap secara lengkap 


\section{UCAPAN TERIMA KASIH}

Ucapan terima kasih kami sampaikan kepada RSUP Dr.Kariadi Semarang yang telah memberikan izin untuk pengambilan data. Selain itu, ucapan terima kasih kami sampaikan juga kepada responden penelitian yang telah meluangkan waktunya dan bersedia untuk diwawancara.

\section{REFERENSI}

1. Kementerian Kesehatan RI. Undang-undang Nomor 44 Tahun 2009. (2009).

2. Kementerian Kesehatan RI. Keputusan Menteri Kesehatan RI Nomor 129 Tahun 2008. (2008).

3. Kementerian Kesehatan RI. Peraturan Menteri Kesehatan RI Nomor 269 tahun 2008. Kementerian Kesehatan RI (2008).

4. Pamungkas, F. et al. Identifikasi Ketidaklengkapan Dokumen Rekam Medis Rawat Inap di RSUD Ngudi Waluyo Wlingi Identification of Incomplete Inpatient Medical Record Documentation at RSUD Ngudi Waluyo Wlingi. 28, 124-128 (2014).

5. Winarti, S. S. Analisis Kelengkapan Pengisisan dan pengembalian Rekam Medis Rawat Inap Rumah Sakit. J. Adm. Kesehat. Indones. 1, 345351 (2013).

6. Djam'an Satori. Metodologi Penelitian Kualitatif. (Alfabeta, 2011).

7. Wijaya, L. \& Dan, S. INFORMASI KESEHATAN II : INFORMASI KESEHATAN II : (2017).

8. Gemala $\mathrm{R}$ Hatta. Pedoman Manajemen Informasi Kesehatan di Sarana Pelayanan Kesehatan. (2008).

9. Anggraeni, D., Hakim, L. \& I, C. W. Evaluasi Pelaksanaan Sistem Identifikasi Pasien di Instalasi Rawat Inap Rumah Sakit Evaluation on Patient Identification System Implementationin Hospital' s Inpatient Unit. J. Kedokt. Brawijaya 28, 99-104 (2014).

10. Febrianti, L. N. \& Sugiarti, I. Kelengkapan Pengisian Formulir Laporan operasi Kasus Bedah obgyn Sebagai Alat Bukti Hukum. J. Manaj. Kesehat. Indones. 7, 1-9 (2019).

11. Ekonomi, S. Program studi manajemen fakultas ekonomi universitas muhammadiyah purworejo 2017. (2017). 